\title{
DEFINIÇÃO DAS UNIDADES DE RELEVO NO MUNICÍPIO DE JAGUARI - RS
}

\author{
Eloisa Penna da Rosa ${ }^{(a)}$, Romario Trentin $^{(b)}$, Daniélli Flores Dias ${ }^{(\mathrm{c})}$, Vinicius Silveira dos \\ Santos ${ }^{(\mathrm{d})}$
}

(a) Departamento de Geociências/Universidade Federal de Santa Maria, Email: eloisapenna@ hotmail.com

(b) Departamento de Geociências/Universidade Federal de Santa Maria, Email: romario.trentin@ gmail.com

(c) Departamento de Geociências/Universidade Federal de Santa Maria, Email: daniellidias08@ gmail.com

(d) Departamento de Geociências/Universidade Federal de Santa Maria, Email: viniciusgeografia93@ gmail.com

\section{EIXO: SISTEMAS GEOMORFOLÓGICOS: ESTRUTURA, DINÂMICA E PROCESSOS}

\section{Resumo}

O presente trabalho propõe um mapeamento das unidades de relevo presentes no município de Jaguari, que localiza-se na região centro-oeste do Estado do Rio Grande do Sul, entre as coordenadas

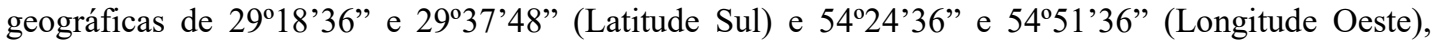
limitando-se com os seguintes municípios: São Francisco de Assis, São Vicente do Sul, Mata, Toropi, Jari, Santiago e Nova Esperança do Sul. As unidades de relevo foram delimitadas a partir do cruzamento entre a hipsometria e a declividade, utilizando a metodologia desenvolvida pelo Instituto de Pesquisas Tecnológicas (IPT). As unidades estão distribuídas entre cinco diferentes classes do seguinte modo: Áreas Planas, Associação de Morros e Morrotes, Colinas Onduladas, Colinas de Altitude e Morros e Morrotes Isolados.

Palavras chave: Unidades de Relevo. Jaguari.

\section{Introdução}

O relevo assume importância fundamental no processo de ocupação do espaço geográfico, sendo que as formas de apropriação respondem pelo comportamento da paisagem e das suas consequências, tornando o seu estudo de grande relevância para contribuir no processo de ordenamento territorial. O relevo de uma região é caracterizado através da associação de diferentes atributos, tais como: hipsometria, declividade, comprimento e amplitude das encostas, através da delimitação de alguns perfis topográficos.

De acordo com Burgos (2009) a cartografia geomorfológica surge como instrumento importante na espacialização dos fatores geomorfológicos, permitindo representar as formas de relevo e suas relações com a estrutura e processo, assim como a dinâmica dos processos.

Os mapeamentos geomorfológicos são de grande importância nas melhores formas de uso e manejo de determinada área. Sendo assim, Ross (1992) destaca que os estudos geomorfológicos e ambientais, podendo ser detalhados ou regional, obedecem as necessidades político- 
administrativas, funcionando como instrumento de apoio técnico aos diferentes interesses políticos e sociais.

De acordo com Silva (2002), os mapeamentos geomorfológicos e sua representação cartográfica propícia compreender a dinâmica de evolução da paisagem no decorrer do tempo geológico, além de fornecer apoio para o uso da terra e recursos naturais.

Neste contexto, insere-se o presente trabalho que objetiva realizar o mapeamento das unidades de relevo de Jaguari, município localizado na porção centro-oeste do estado do Rio Grande do Sul, entre as

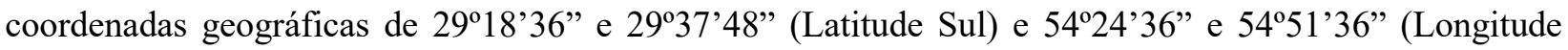
Oeste), limitando-se com os seguintes municípios: São Francisco de Assis, São Vicente do Sul, Mata, Toropi, Jari, Santiago e Nova Esperança do Sul. Possui uma população de 11.473 habitantes e uma área territorial de $673,401 \mathrm{~km}^{2}$, segundo os dados do IBGE (2010). A Figura 1 representa a localização do município de Jaguari.



Figura 1 Localização do município de Jaguari - RS 
XVII Simpósio Brasileiro

de Geografia Física Aplicada

I Congresso Nacional

de Geografia Física
OS DESAFIOS DA GEOGRAFIA FÍSICA NA FRONTEIRA DO CONHECIMENTO

Instituto de Geociências - Unicamp

Campinas - SP

28 de Junho à 02 de Julho de 2017

\section{Metodologia do Trabalho}

Em um primeiro momento foi feito o levantamento bibliográfico a partir de bibliografias referentes ao tema proposto. Para a construção dos mapas temáticos (hipsometria, declividade e unidades de relevo), as informações foram obtidas a partir da Base Vetorial Continua do Estado do Rio Grande do Sul, desenvolvida pelo Centro de Ecologia da Universidade Federal do Rio Grande do Sul (Hasenack e Weber, 2010), além do Modelo Digital de Elevação (MDE) construído através das imagens de RADAR da missão Shuttle Radar Topography Mission (SRTM).

Utilizou-se o softwares Arcgis ArcGIS ${ }^{\circledR} 10.1$ desenvolvido pela Environmental Systems Research Institute (ESRI) e o CorelDRAW ${ }^{\circledR} \mathrm{X} 6$ desenvolvido pela Corel Inc., para a finalização e layout dos mapas temáticos. Os trabalhos de campo serviram para conhecer as formas de relevo, as litologias, os tipos de solos e o uso e ocupação do município de Jaguari.

O mapa hipsmétrico foi construído através das imagens de RADAR da missão Shuttle Radar Topography Mission (SRTM), com resolução espacial de 30 metros. As classes foram definidas através de quebras do relevo e arredondadas por meio de procedimentos matemáticos. Diante disso, foram estabelecidas as seguintes classes: < 100m; 100-200m; 200-300m; 300-400m; >400m.

O mapa de declividade foi elaborado utilizando as classes propostas pelo Instituto de Pesquisas Tecnológicas (IPT) dividindo o terreno em quatro classes: menores que $2 \%$ representa as áreas planas, associadas em geral as drenagens onde predominam os processos de acumulação e sujeitas a inundação; de 2 - 5\% são áreas com baixas declividades, podendo ocorrer processos erosivos significativos; de 5 $15 \%$ onde predominam os processos erosivos e considerada limite para a mecanização agrícola e maiores que $15 \%$ são áreas que possuem várias restrições de uso, sendo amparada pela legislação ambiental.

Por fim, o mapa de unidades de relevo foi elaborado a partir do cruzamento entre a hipsometria e a declividade, utilizando a metodologia desenvolvida pelo Instituto de Pesquisas Tecnológicas (IPT). Sendo que as classes definidas foram as seguintes: Áreas Planas, Associação de Morros e Morrotes, Colinas Onduladas, Colinas de Altitude e Morros e Morrotes Isolados.

\section{Resultados e Discussões}

O município de Jaguari apresenta a menor cota altimétrica o nível de 78 metros junto a planície do rio Jaguari e a maior cota altimétrica de 450 metros na região centro-oeste do município, resultando em uma amplitude altimétrica de 372 metros. Esta diferença altimétrica pode ser explicada pelo fato de que Jaguari 
encontra-se em uma região geomorfológica de transição entre a Depressão Periférica (áreas mais rebaixadas) e o Planalto Meridional (áreas mais elevadas).

O município foi dividido em cinco áreas de altitudes distintas para uma melhor visualização da hipsometria do município como mostra a Figura 2. As porções de menores altitudes no município, ou seja, menores que 100 metros, estão localizadas nas áreas junto ao rio Jaguari e representam 8,98\% da área total de Jaguari. As altitudes entre 100 e 200 metros, estendem-se do norte ao sul do município. Corresponde a $48,10 \%$ da área total do município, sendo a maior classe hipsométrica em extensão, onde se localiza a área urbana de Jaguari. As altitudes entre o intervalo de 200 e 300 metros avançam do norte ao centrooeste do município, representando $23,02 \%$ da área total de Jaguari. O intervalo de 300 a 400 metros correspondem a parte norte do município. Essa classe ocupa $32 \%$ da área total do município. Por fim, as maiores altitudes correspondem a uma área de $1,58 \%$ do total do município, com altitudes superiores a 400 metros, na região sudoeste do município.

A declividade é a inclinação da superfície do terreno em relação ao plano horizontal, expressa em graus ou porcentagens. A declividade de encostas é um elemento muito estudado, já que é um dos fatores que contribuem em diversos processos de vertente, como os movimentos de massa, e processos erosivos, além de interferirem nos processos de uso e ocupação dos solos. A Figura 3 apresenta o mapa de declividade do município de Jaguari, onde o terreno foi dividido em quatro classes. As classes foram classificadas em: menores que $2 \%$, representando $15,15 \%$ da área total do município, de $2 \%$ - 5\% corresponde a $16,99 \%$ da área em estudo, de 5\%-15\% ocupa a maior área do município, o que corresponde a 39, 63\% da área total e maiores que $15 \%$, representando $28,23 \%$ do total da área do município.

A partir dos resultados obtidos através das características das vertentes como declividade, amplitude, comprimento e hipsometria, analise das drenagens e o traçado de alguns perfis definiu-se as unidades de relevo no município de Jaguari. Sendo assim, foram classificadas cinco unidades de relevo (Figura 4).

Unidade de Morros e Morrotes Isolados: é constituída por áreas íngremes, situadas em porções isoladas do município. Representa morros testemunhos isolados e morrotes com declividade maiores que $15 \%$ e amplitudes de 250 metros. Indicam os processos que provocam o recuo do planalto pela resistência dos materiais e as linhas de fraturas. Representa apenas $0,55 \%$ da área total do município.

Unidade de Colinas: caracteriza-se por apresentar um relevo levemente ondulado, com declividades entre $2-5 \%$, estende-se do centro ao sul do município, correspondendo a 30,05\% da área total de Jaguari.

Unidade de Associação de Morros e Morrotes: essa unidade situa-se próximo ao rebordo (ao norte do município), caracterizando a zona de transição entre o Planalto Meridional e a Depressão Periférica no Estado gaúcho. Apresenta declividades maiores que 15\%, caracterizando um relevo fortemente ondulado. Representa a maior área com $39,16 \%$ da área total em estudo. 


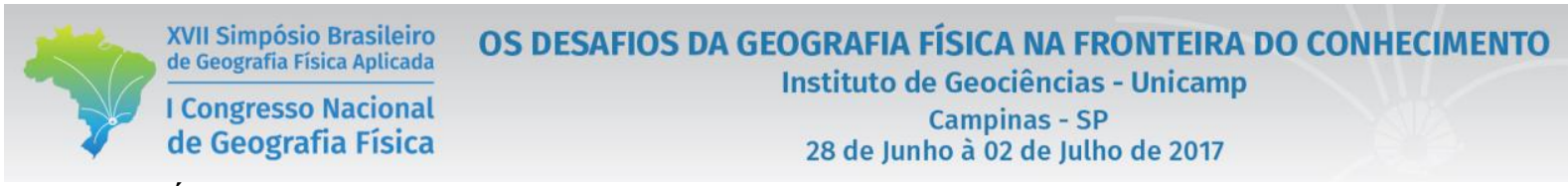

Unidade de Áreas Planas: caracteriza-se por apresentar relevo plano, com declividade menores que $2 \%$ e amplitudes de 20 metros, vindo a ocorrer junto as principais drenagens do município. Consideradas áreas de acumulação ou várzea, localiza-se próximo ao rio Jaguari e Jaguarizinho. Ocupa uma área total de $15,63 \%$ do município.

Unidade de Colinas de Altitude: apresenta amplitude de 80 metros. Estende-se próxima ao rebordo do Planalto Meridional ao norte do município, com declividades de 5 - 15\%. Representa $14,59 \%$ da área total de Jaguari.

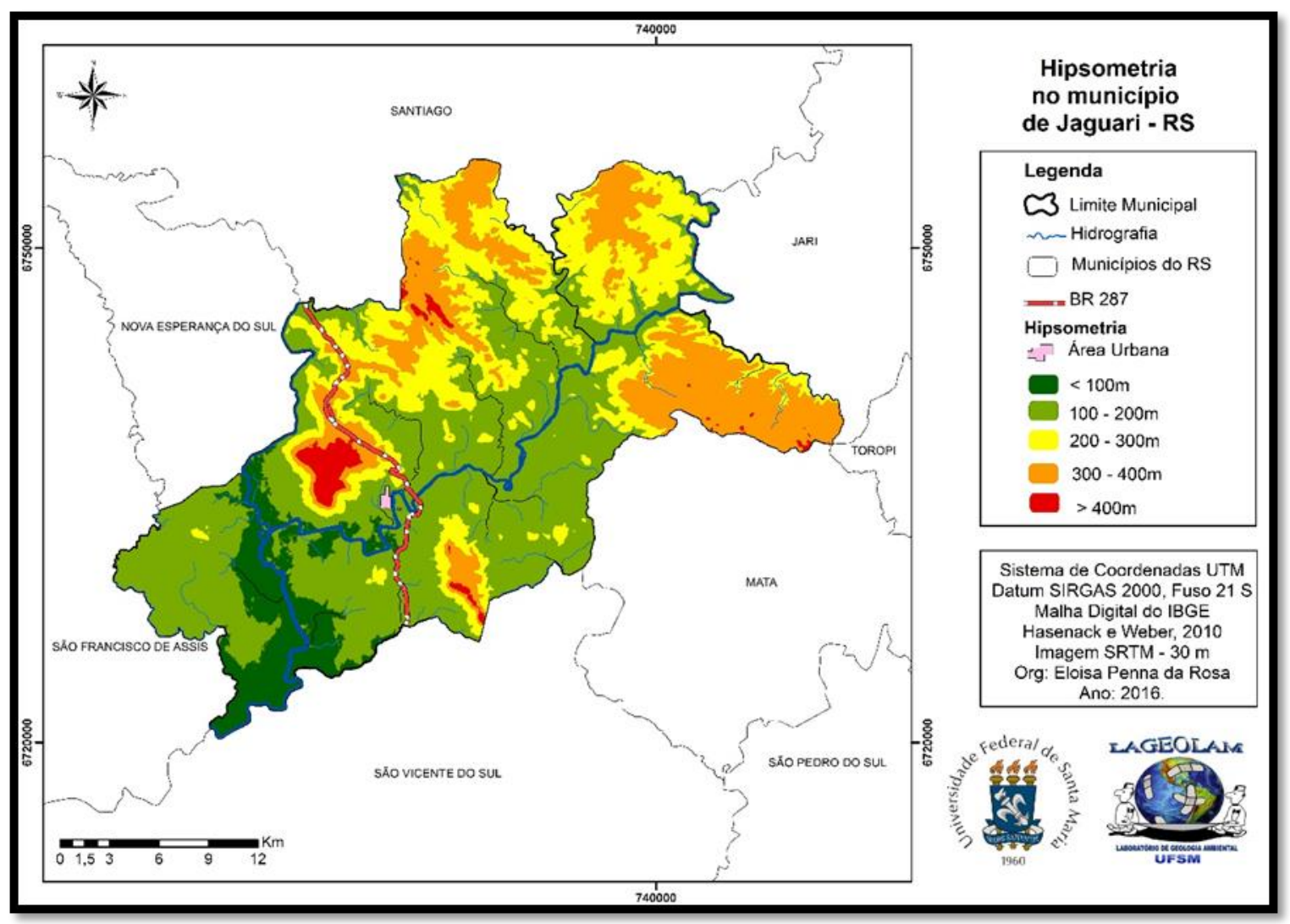

Figura 2 Hipsometria do município de Jaguari - RS 
XVII Simpósio Brasileiro de Geografia Fisica Aplicada

I Congresso Nacional de Geografia Física
OS DESAFIOS DA GEOGRAFIA FÍSICA NA FRONTEIRA DO CONHECIMENTO

Instituto de Geociências - Unicamp

Campinas - SP

28 de Junho à 02 de Julho de 2017

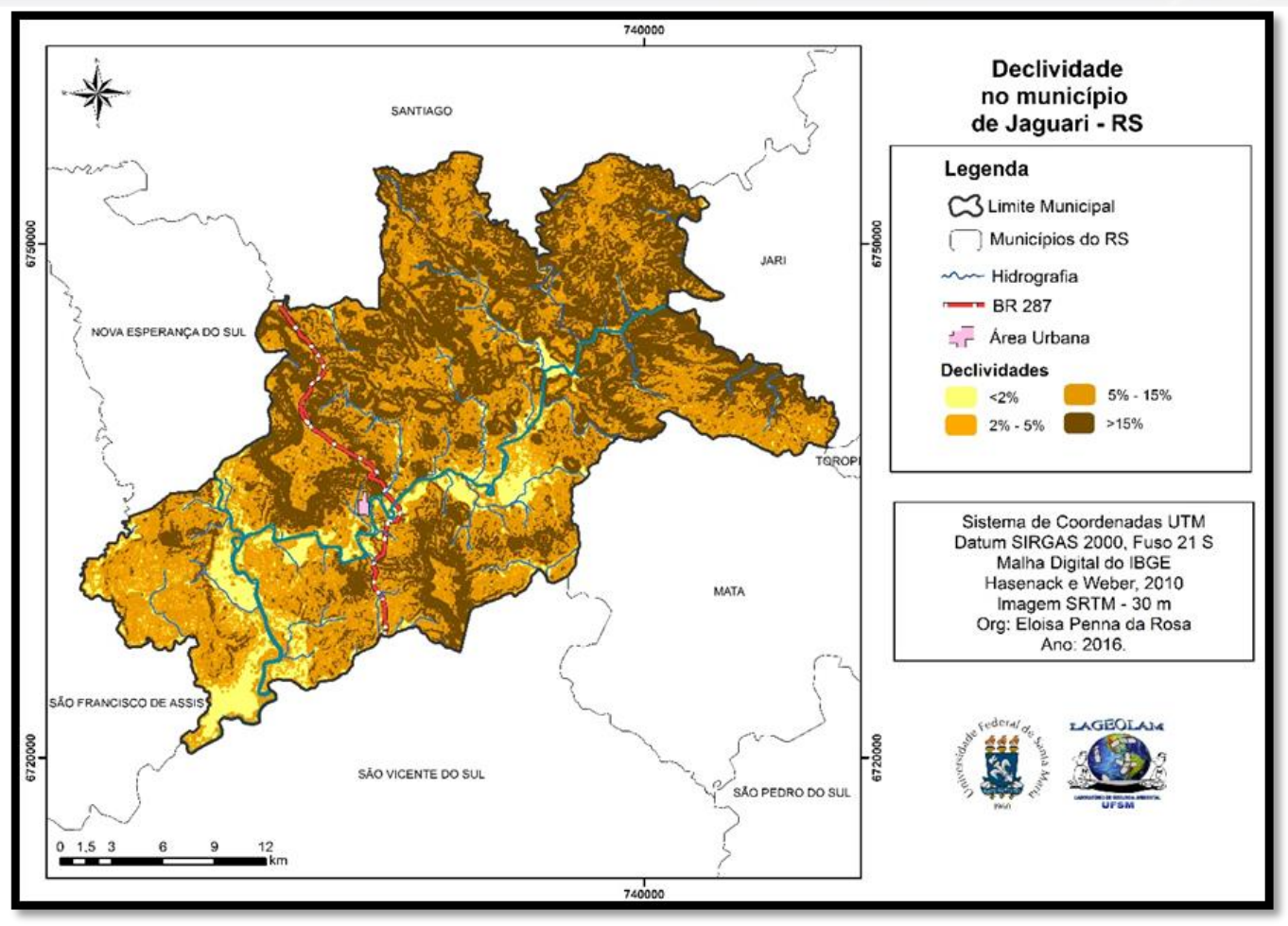

Figura 3 Declividade do município de Jaguari - RS

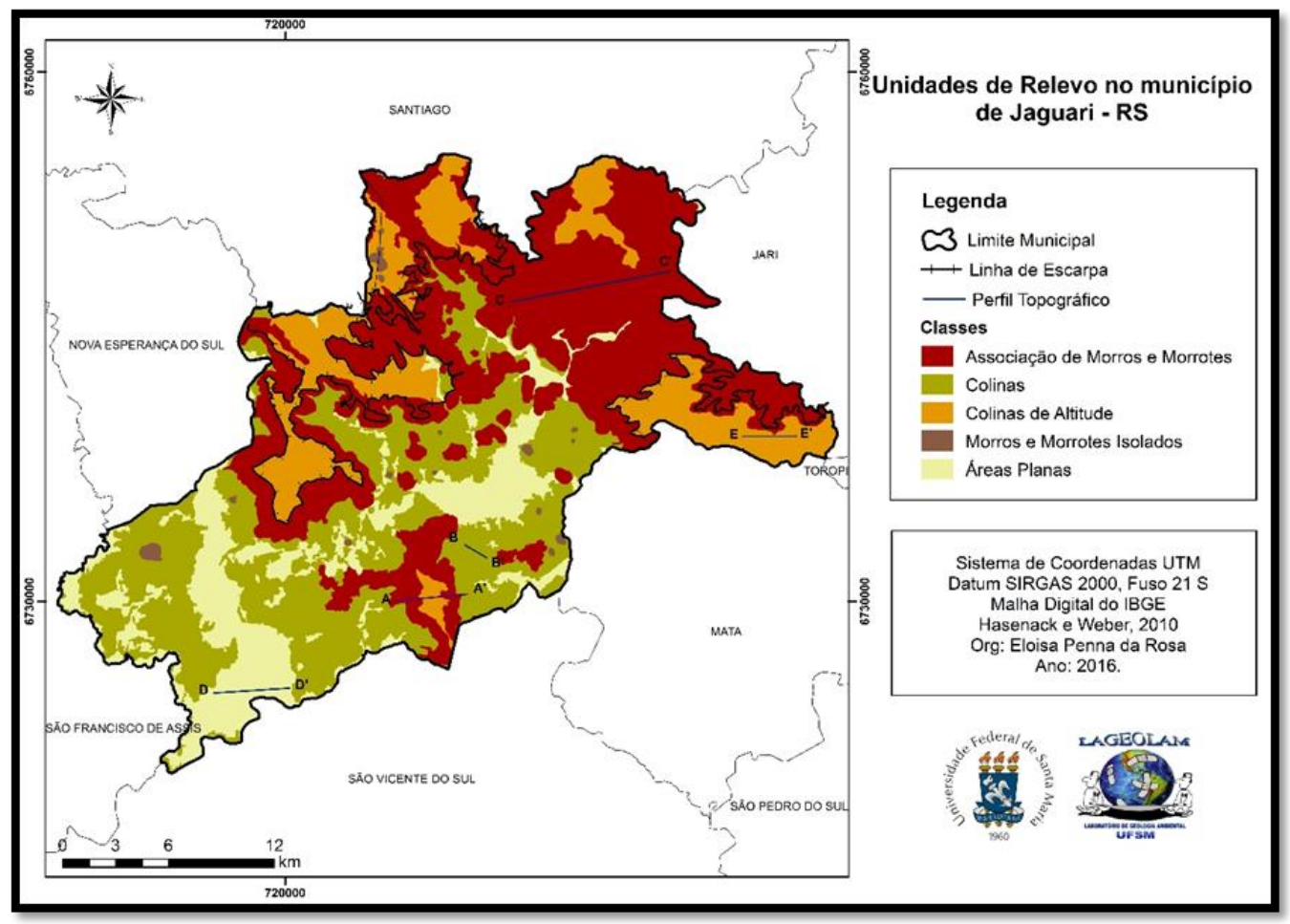

Figura 4 Unidades de Relevo do município de Jaguari - RS 


\section{Considerações Finais}

Através da hipsometria e da declividade foi possível descrever o relevo do município de Jaguari. Com a realização desse trabalho podemos concluir que o município apresenta a maior parte de sua área em altitudes entre 100 e 200 metros, onde localiza-se inclusive a área urbana de Jaguari, com cerca de 48,10\% da área total.

Em relação a declividade a classe com maior representatividade dentro do município encontra-se entre 5 $15 \%$, correspondendo a $39,63 \%$ da área total.

Observa-se que as unidades de relevos predominantes no município de Jaguari correspondem a Associação de Morros e Morrotes e as Colinas, sendo que juntas representam 69,21\% da área total do município. Sendo que, os Morros e Morrotes Isolados correspondem a apenas $0,55 \%$ da área total estudada.

Por fim, conclui-se que os resultados apresentados ao longo do trabalho demonstram a importância de conhecer as características do relevo e seus aspectos para o auxílio da elaboração e implantação de políticas públicas de manejo adequado e tomadas de decisões.

\section{Bibliografia}

BURGoS, C. D. Mapeamento Geomorfológico Aplicado a Análise Ambiental: Estudo de Caso Serra da Jaqueçaba e seu Entorno (Espírito Santo - Brasil). 96f. Trabalho de Graduação. Universidade Federal do Espírito Santo, Vitória, 2009.

HASENACK, H.; WEBER, E. Base cartográfica vetorial contínua do Rio Grande do Sul. Série Geoprocessamento. Centro de Ecologia/UFRGS. 1 DVD. 2010.

INSTITUTO DE PESQUISAS TECNOLÓGICAS (IPT). Mapeamento Geomorfológico do Estado de São Paulo. São Paulo. Escala 1:50.000, v. 2, p. 130, 1981.

INSTITUTO BRASILEIRO DE GEOGRAFIA E ESTATÍSTICA. Dados do Município de Jaguari. Disponível em: <http://cidades.ibge.gov.br/xtras/perfil.php?codmun=431110>. Acesso em: 10 mar. 2016.

ROSS, J. L. S. O registro cartográfico dos Fatos Geomórficos e a Questão da Taxonomia do Relevo, Revista do Departamento de Geografia, FFLCH-USP, São Paulo, n.6, p.17-29, 1992.

SILVA, T.M. 2002. A Estruturação Geomorfológica do Planalto Atlântico no Estado do Rio de Janeiro. Rio de Janeiro: Inst. Geoc. PPGG/UFRJ. 265p. (Tese Dout.). 


$\begin{gathered}\text { XVII Simpósio Brasileiro } \\ \text { de Geografia Fisica Aplicada }\end{gathered}$
$\begin{aligned} & \text { ICongresso Nacional } \\ & \text { de Geografia Física }\end{aligned}$

